\title{
Management of orbital floor fractures-A case series
}

\section{Devakumari Shanmugam ${ }^{1}$, Vijhayapriya Thanasekaran²}

${ }^{1}$ Associate Professor and Head, Department of Dentistry, Indira Gandhi Medical College and Research Institute (Government), Puducherry-605008, India, ${ }^{2}$ Associate Professor, Department of Ophthalmology, Indira Gandhi Medical College and Research Institute (Government), Puducherry-605008, India

\section{A B S T R A C T}

Orbital floor fractures are the most challenging fractures to be managed in maxillofacial region. They are diagnosed in isolation or in combination with mid face fractures, Lefort fractures and zygomatic fractures. The treatment depends on the displacement of the fractured bones and the manifestations of muscle entrapment elicited by clinical examination and radiographic assessment. The timing of repair is of paramount importance and decided on the case to case basis. Proper surgical approach along with appropriate implant placement is the key to success. This paper describes a series of 11 patients operated in IGMC\&RI, Puducherry for orbital floor fractures from 2010 to 2019.

Key words: Orbital floor fractures; Blow out fractures; Transconjunctival approach; Diplopia; Enophthalmos; Infra orbital approach

\section{Access this article online}

Website:

http://nepjol.info/index.php/AJMS DOI: 10.3126/ajms.v12i5.33930

E-ISSN: 2091-0576

P-ISSN: $2467-9100$

Copyright (c) 2021 Asian Journal of Medical Sciences

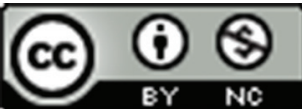

This work is licensed under a Creative Commons Attribution-NonCommercial 4.0 International License.

\section{INTRODUCTION}

Management of orbital floor fractures requires special consideration because observation or the timely surgical management has to be properly ascertained at the earliest. The decision on the management depends on the team comprising of maxillofacial surgeon, ophthalmologist and the radiologist. Adhering to the strict protocols prevents both aesthetic and functional deformities.

\section{PATIENTS AND METHODS}

The surgical planning and outcomes of 11 patients operated in IGMC\&RI from 2010 to 2019 for isolated or combined orbital floor fractures are discussed in detail in this paper. Informed consent and consent to publish patient photographs were obtained prior to surgery. All patients who were operated for orbital floor fractures were Males and the etiology of fracture being RTA. Maxillofacial trauma patients who reported within 14 days of injury only were operated. Patients with co morbid illness or patient with impaired level of consciousness due to head injury were not included in this series. Isolated blow out fractures or combined with zygoma, Lefort and pan facial fractures were operated (Table 1).

\section{CLINICAL EXAMINATION}

It includes thorough palpation of bony margins, looking for the presence of proptosis, Enophthalmous, vertical dystopia and evaluation of ocular movements. Eliciting diplopia and recording it is very important. Clinical signs like subconjunctival haemorrhage, chemosis and eccymosis were recorded. 


\section{Table 1: List of associated fractures}

$\begin{array}{lll}1 & \text { Pure blow out fractures } & 1 \\ 2 & \text { Orbital floor with associated Lefort fractures } & 2 \\ 3 & \text { Orbital floor with Zygomatico maxillary complex fractures } & 5 \\ 4 & \text { Orbital floor with associated mandibular fractures } & 1 \\ 5 & \text { Orbital floor with associated pan facial fractures } & 2\end{array}$

Most of the orbital trauma is associated with ocular injuries. A complete eye examination is done by referring the patient to the department of ophthalmology immediately to rule out orbital compartment syndrome which includes retrobulbar haemorrhage and traumatic optic neuropathy. Further ophthalmologic examination includes vision, eye pressure, ocular motility, pupil examination, visual field, slit lamp ocular examination and retinal examination. If the other eye is compromised, risk vs benefit in operating the injured eye was evaluated.

\section{RADIOLOGIC EXAMINATION}

Computed tomography is the gold standard diagnostic tool. A CT scan with slice thickness of less than $2 \mathrm{~mm}$ was ordered. Sagital, axial and coronal slices were viewed. Ct scan with $3 \mathrm{D}$ reconstruction gives the exact clinical picture of the scenario. Both coronal and sagital views can be used to assess the orbital soft tissue, to see for fat herniation and the ocular muscle entrapment. The sagital view allows for evaluation of the orbital floor and the presence of the posterior ledge for implant support. The medial wall is best seen in an axial view. The size of the defect can also be measured. A size of 1 $\mathrm{cm}^{2}$ or more than 50 percent of floor involvement are good candidates for immediate intervention without any need for observation. Coronal CT is predictive of postoperative enophthalmos. When there is rounding of the inferior rectus or if the inferior rectus shows a more vertical orientation (the height to width ratio is greater than or equal to 1 ), then immediate intervention is absolutely necessary.

\section{Surgical planning}

The precautions instructed to the patients were -

Not to blow the nose, to avoid displacement of bony fragments supporting the orbit.

Cold compression and head elevation advised for the reduction of orbital oedema.

Presence of complete closure of eyelids was elicited and if not possible temporary tarsorhapy or eye shield was provided.

Immediate intervention is planned in cases of large fracture more than $1 \mathrm{~cm}$ and in cases of muscle entrapment elicited both clinically (forced duction test) and radio logically (rounding of inferior rectus and vertically entrapped rectus muscle).

Surgery is delayed in patients with oedema to prevent orbital compartment syndrome and in cases of diplopia without much of muscle involvement. Diplopia in normal gaze not resolving for more than 2 weeks was taken up for surgery.

\section{Surgical procedure}

The surgical approach is largely dependent on the size and location of fracture, type of associated fracture and the surgeon's experience.Transconjunctival approach and infra orbital approach was preferred. In case of communition and loss of infra orbital rim, the infra orbital approach (6 patients) was used. In one of the patient iliac crest was used to reconstruct the floor and the rim using infra orbital approach [Figures 1-6]. Trans-conjunctival incisions [Figures 7-9] (5 patients) are widely preferred and used in exposure of the orbital floor because of inconspicuous scar and low complication rate.

We used auto grafts such as iliac crest in one patient and alloplastic material, titanium mesh (1 $\mathrm{mm}$ thick) was placed in 10 patients. Both the grafts were biocompatible and radio opaque. The titanium implant is placed on the posterior ledge or cantilevered to the posterior ledge. In either of the approaches infra orbital rim was reached and a dissection 20 degree to the cephalic region was done to expose the floor. Careful dissection is done from periphery to the centre of the defect. Infra orbital nerve is identified and the orbital content is lifted from the periphery. A malleable retractor helps to lift and protect the orbital contents throughout the procedure. Bone margins are examined for stability to support the implant. The titanium mesh is adapted and kept in the floor with due precaution of not to injure the optic nerve. If the posterior ledge was difficult to be identified then the mesh is fixed on to the anterior part of infra orbital rim and cantilevered to the posterior ledge. A forced duction test is performed after the placement of the mesh to rule out muscle entrapment otherwise it may lead to post-operative diplopia. The wound is closed in layers. Post operatively eye drops and topical ophthalmic ointments were given to moisturize the cornea, especially if oedema affects the eyelid closure.

\section{Complications}

Three cases (1- infra orbital approach and 2 - transconjunctival approach) had mild ectropion although not complained by the patients. Enophthalmous was present in 3 patients; this is due to the communition of the surrounding bone and delayed reporting after the injury. None of the patients had diplopia. 
Case -1

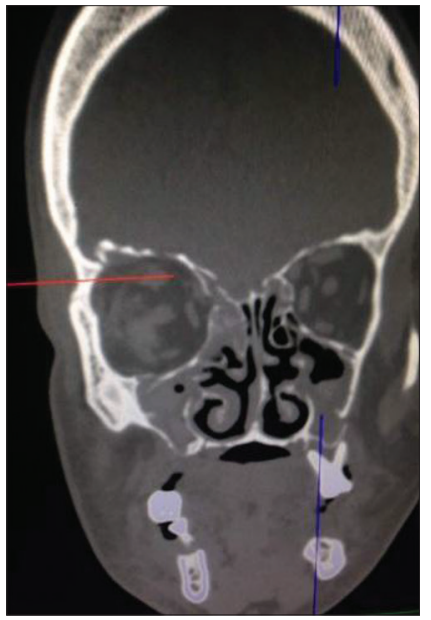

Figure 1: Pre operative CT

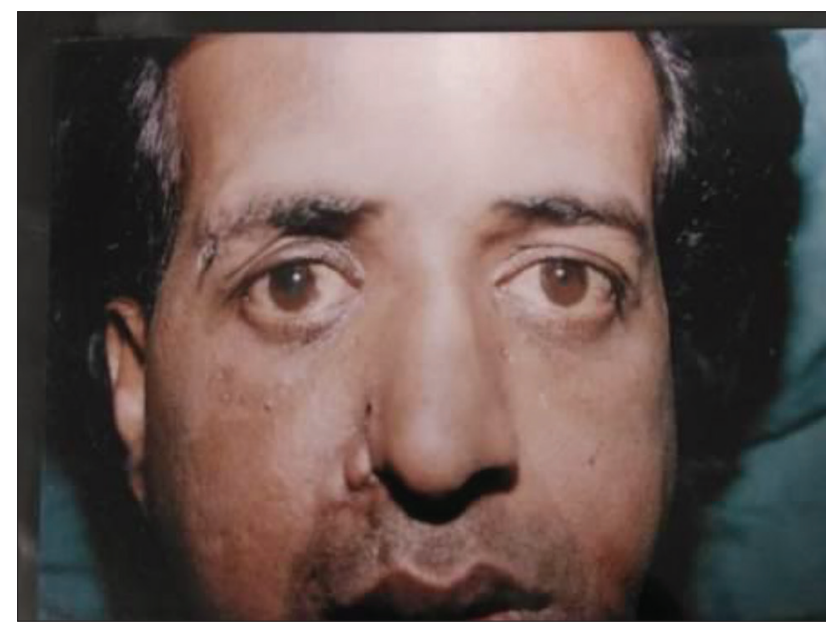

Figure 2: Pre operative image showing Enophthalmos

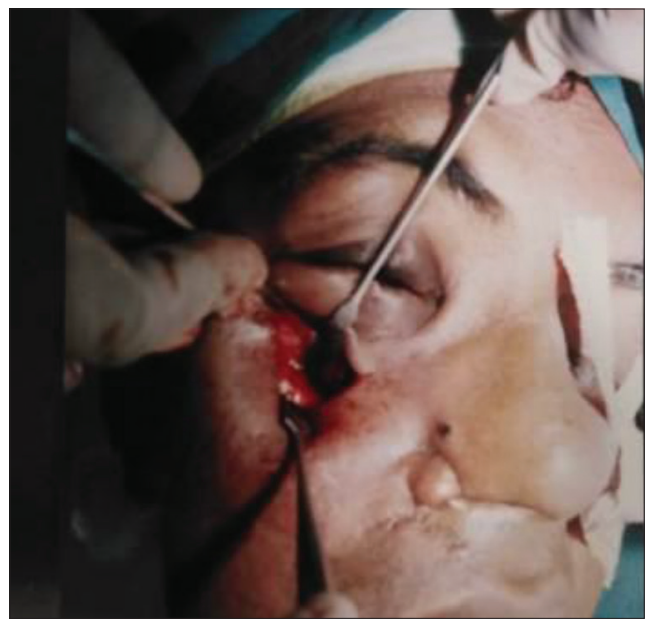

Figure 3: Exposure by infra orbital approach

\section{DISCUSSION}

Kreidl et al observed that in patients with orbital fractures, associated ocular injuries were present in up to $29 \%$ of the patients. ${ }^{1}$ It is important to refer for an eye examination

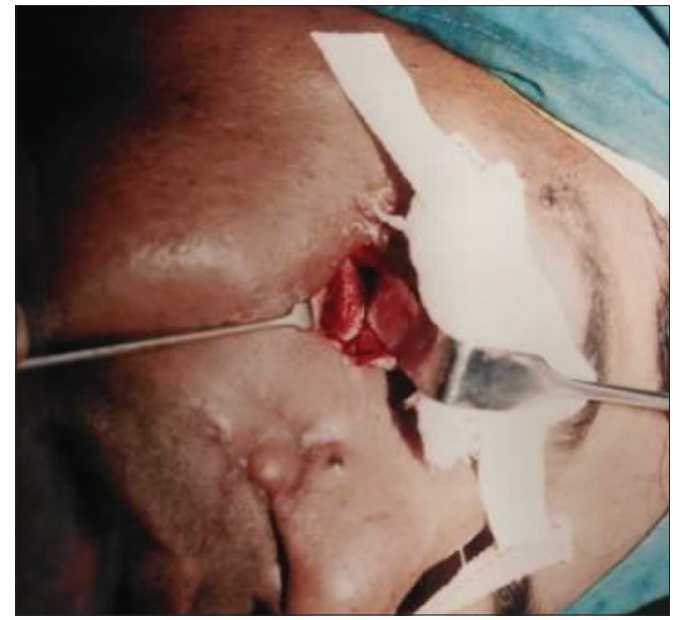

Figure 4: lliac crest-autograft-reconstruction of the floor and the rim

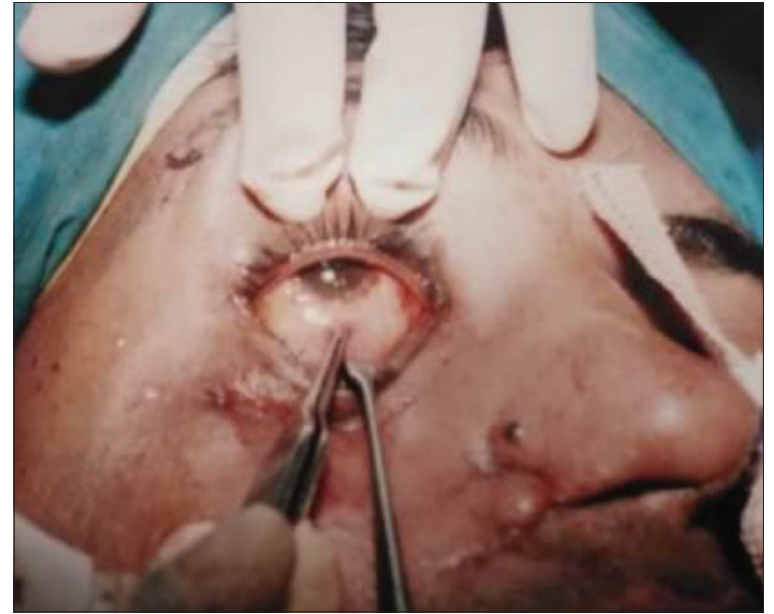

Figure 5: Forced duction test after placement of the graft

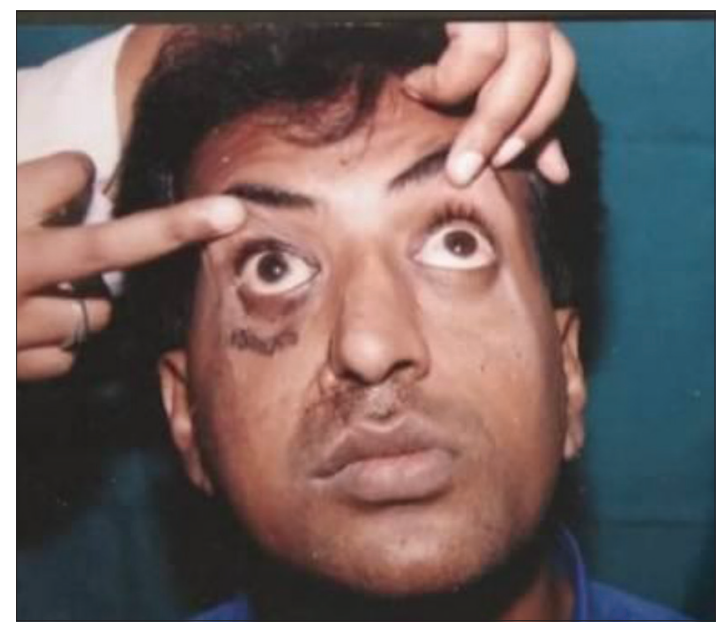

Figure 6: Post operative 1 week with no complaints of diplopia/ restriction in eye movements

to assess the risk of vision loss or defects in vision. Blindness associated with orbital fractures has been reported at $0.7 \%-10 \%{ }^{2}$ Traumatic optic neuropathy is reported to occur in $3 \%$ of the isolated orbital fractures. ${ }^{3}$ 
Case -2

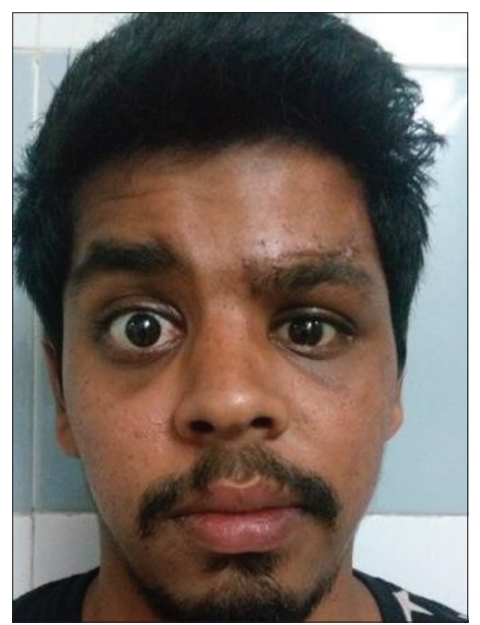

Figure 7: Pre-Operative enopthalmos and diplopia -12 th day of injury

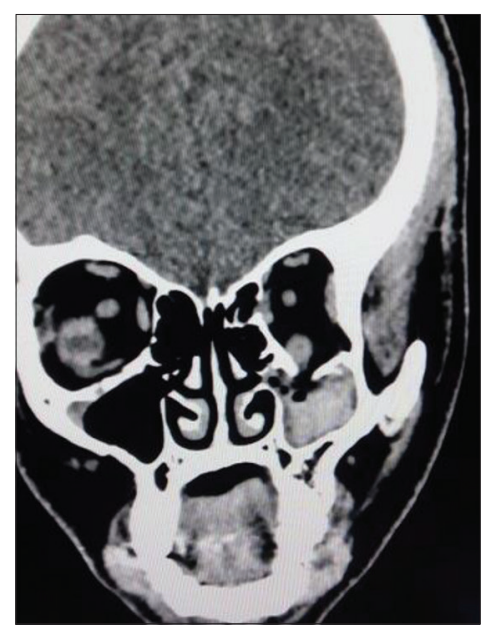

Figure 8: Coronal CT-Rounding of inferior rectus

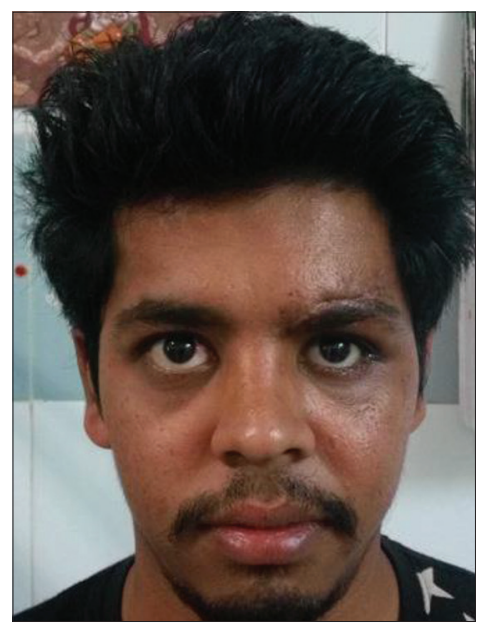

Figure 9: Post operative-transconjunctival approach with titanium mesh in place- mild enophthalmos and no complaints of diplopia

Indication for immediate intervention is the clinically significant enophthalmos at the time of injury. These cases need surgical repair to prevent enophthalmos and some surgeons recommend early intervention for this type of large defect. ${ }^{4}$ The subciliary approach has been associated with more complications like ectropion in approximately $12.9 \%$ of cases. ${ }^{5}$ The sub tarsal approach is associated with lesser ectropion and if done properly result in an inconspicuous scar $(1 \%-3 \%){ }^{6}$ Transconjunctival approach is preferred in the management of orbital floor fractures because it leads to no visible scar and the complications were less than $1 \%{ }^{7}$ Bly et al claimed that the use of image guidance significantly decrease the incidence of postoperative diplopia and reduced the need for revision surgery in fractures that involved multiple orbital walls. ${ }^{8}$ Cheung et al reviewed studies involving 172 patients in which endoscopic approaches were used for orbital wall fractures. ${ }^{9}$ The iliac crest, calvarium, nasal, maxillary, and mandibular bone was used as autografts, with the first two being the most commonly used. ${ }^{10}$

Titanium is biocompatible, can be easily adjusted, fits well in complex orbital defects, provides strong support, does not alter its shape or location over time and it can be easily fixed to adjacent bone. It has excellent osseointegration and can be easily sterilized. The cut edges are prone to damage the peri orbital soft tissue during placement. ${ }^{11}$ Using preoperative CT data, a patient-specific implant (PSI) can be specifically designed from the non-affected orbit. These ideal custom-made implants are intended to reduce the need for intra operative manipulation, thus reducing operative time with more accurate reconstruction. ${ }^{12}$

\section{CONCLUSION}

Management of orbital floor fractures warrants proper planning regarding conservative management, immediate and delayed repair. This is accomplished by clinical and radiological examination done in a phased manner. A flaw in the treatment planning leads to both aesthetic and functional eye defects and may lead to time consuming revision surgeries.

\section{REFERENCES}

1. Kreidl KO, Kim DY and Mansour SE. Prevalence of significant intraocular sequelae in blunt orbital trauma. Am J Emerg Med. 2003;21(7):525-528.

https://doi.org/10.1016/j.ajem.2003.08.009

2. Dancey A, Perry M and Silva DC. Blindness after blunt facial trauma: are there any clinical clues to early recognition? J Trauma. 2005;58(2):328-335.

https://doi.org/10.1097/01.TA.0000135353.28388.B0

3. He D, Blomquist PH, Ellis E., 3rd Association between ocular injuries and internal orbital fractures. J Oral Maxillofac Surg. 2007;65(4):713-720.

https://doi.org/10.1016/j.joms.2006.09.006

4. Liao JC, Elmalem VI, Wells TS and Harris GJ. Surgical timing and postoperative ocular motility in type B orbital blowout

Asian Journal of Medical Sciences | May 2021 | Vol 12 | Issue 5 
fractures. Ophthal Plast Reconstr Surg. 2015;31(1):29-33. https://doi.org/10.1097/IOP.0000000000000161

5. Holtmann B, Wray RC and Little AG. A randomized comparison of four incisions for orbital fractures. Plast Reconstr Surg. 1981;67(6):731-737.

https://doi.org/10.1097/00006534-198106000-00003

6. Ridgway EB, Chen C, Colakoglu S, Gautam S and Lee BT. The incidence of lower eyelid malposition after facial fracture repair: a retrospective study and meta-analysis comparing subtarsal, subciliary, and transconjunctival incisions. Plast Reconstr Surg. 2009;124(5):1578-1586.

https://doi.org/10.1097/PRS.0b013e3181babb3d

7. Westfall CT, Shore JW, Nunery WR, Hawes MJ and Yaremchuk MJ. Operative complications of the transconjunctival inferior fornix approach. Ophthalmology. 1991;98(10):1525-1528. https://doi.org/10.1016/S0161-6420(91)32094-3

8. Bly RA, Chang SH, Cudejkova M, Liu JJ and Moe KS. Computerguided orbital reconstruction to improve outcomes. JAMA Facia
Plast Surg. 2013;15(2):113-120.

https://doi.org/10.1001/jamafacial.2013.316

9. Cheung $\mathrm{K}$, Voineskos SH, Avram $\mathrm{R}$ and Sommer DD. A systematic review of the endoscopic management of orbital floor fractures. JAMA Facial Plast Surg. 2013;15(2):126-130. https://doi.org/10.1001/jamafacial.2013.595

10. Gunarajah DR and Samman N. Biomaterials for repair of orbital floor blowout fractures: a systematic review. J Oral Maxillofac Surg. 2013;71(3):550-570.

https://doi.org/10.1016/j.joms.2012.10.029

11. Ellis E, 3rd, Tan Y. Assessment of internal orbital reconstructions for pure blowout fractures: cranial bone grafts versus titanium mesh. J Oral Maxillofac Surg. 2003;61(4):442-453. https://doi.org/10.1053/joms.2003.50085

12. Gander T, Essig H, Metzler $P$, Lindhorst D, Dubois L, Rucker M, et al. Patient specific implants (PSI) in reconstruction of orbital floor and wall fractures. J Craniomaxillofac Surg. 2015;43(1):126-130. https://doi.org/10.1016/j.jcms.2014.10.024

\section{Author's contribution:}

DK-Conception and design of the work and reviewed the literature and final approval of the version to be published; VP- Manuscript preparation and Critical revision of the article.

Work attributed to:

Department of Dentistry and Department of Ophthalmology, Indira Gandhi Medical College and Research Institute (Government), Puducherry-605008, India.

Orcid ID:

Dr. Devakumari- (i) https://orcid.org/0000-0001-9166-2285

Dr. Vijhayapriya- (D https://orcid.org/0000-0001-7570-3497 